\title{
Isotopic characterization of vanillin ex glucose by GC-IRMS - New challenge for natural
} vanilla flavour authentication?

Wilde, Amelie Sina; Frandsen, Henrik Lauritz; Fromberg, Arvid; Smedsgaard, Jørn; Greule, Markus

\section{Published in:}

Food Control

Link to article, DOI:

10.1016/j.foodcont.2019.106735

Publication date:

2019

Document Version

Peer reviewed version

Link back to DTU Orbit

Citation (APA):

Wilde, A. S., Frandsen, H. L., Fromberg, A., Smedsgaard, J., \& Greule, M. (2019). Isotopic characterization of vanillin ex glucose by GC-IRMS - New challenge for natural vanilla flavour authentication? Food Control, 106, [106735]. https://doi.org/10.1016/j.foodcont.2019.106735

\section{General rights}

Copyright and moral rights for the publications made accessible in the public portal are retained by the authors and/or other copyright owners and it is a condition of accessing publications that users recognise and abide by the legal requirements associated with these rights.

- Users may download and print one copy of any publication from the public portal for the purpose of private study or research.

- You may not further distribute the material or use it for any profit-making activity or commercial gain

- You may freely distribute the URL identifying the publication in the public portal 


\section{Isotopic Characterization of Vanillin ex Glucose by GC-IRMS} - New Challenge for natural vanilla flavour authentication?

Amelie S. Wilde ${ }^{1 *}$, Henrik Lauritz Frandsen ${ }^{1}$, Arvid Fromberg ${ }^{1}$, Jørn Smedsgaard ${ }^{1}$, Markus Greule ${ }^{2}$

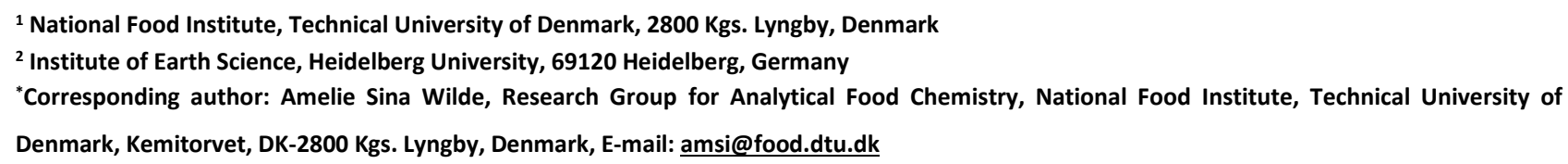

\section{Keywords}

Authenticity; natural vanilla flavor; biovanillin; ${ }^{13} \mathrm{C} /{ }^{12} \mathrm{C}$ ratio; ${ }^{2} \mathrm{H} /{ }^{1} \mathrm{H}$ ratio; Isotope ratio mass spectrometry

\section{Highlights:}

- Carbon and hydrogen isotopic ratio characterisation of vanillin ex glucose

- Database extension of vanilla pods originating from 16 different countries

- Carbon and hydrogen isotopic ratio characterisation of a vanilla hybrid

\section{Abstract}

Vanilla flavour is highly vulnerable to economically motivated adulteration as the main component vanillin can be derived by much cheaper production methods than by the extraction from vanilla pods. The $\delta^{13} \mathrm{C}$ ranges for synthetic vanillin from petroleum and C3 plants are depleted in comparison to the reported $\delta^{13} \mathrm{C}$ range for vanillin from vanilla orchids. However, with the invention of new biosynthetic pathways, vanillin overlapping with the characteristic $\delta^{13} \mathrm{C}$ range reported for vanillin from vanilla pods can be produced. Here, we present site-specific analysis by GC-IRMS of stable carbon and hydrogen isotope ratios of vanillin derived from glucose. This is the first time a $\delta^{13} \mathrm{C}$ value for biovanillin that is higher compared to vanillin from vanilla pods is reported. The possibility to simulate the $\delta^{13} \mathrm{C}$ range of vanillin from vanilla pods by combining vanillin derived from inexpensive sources constitutes an increased risk for fraud being perpetrated while remaining unnoticed.

\section{Introduction}

Vanilla, known as the "Queen" of spices, is one of the most popular flavours in the world and is widely used in food and perfume industries. Vanilla has its origin in Mexico, but it is nowadays cultured in various tropical countries around the equator including Madagascar that supplies more than half of the world production. The genus Vanilla belongs to the family Orchidaceae that comprises more than 100 species. Vanilla planifolia is the orchid with the most economical importance for vanilla production, whereas other species as Vanilla 
tahitensis and Vanilla pompona represent minor sources and are only cultivated in small scales (Dignum, Kerler, \& Verpoorte, 2001). Several hybrids of the different species are known such as the hybrids "Vaitsy" and "Tsy Taitry", which are combinations of $V$. planifolia and V.pompona. Vanilla requires special growth conditions and an elaborate curing procedure (Korthou \& Verpoorte, 2007). The global demand for vanillin, the main compound of the vanilla flavour, was 18.700 tons in 2016 . Less than $1 \%$ of this demand originated from vanilla pods, whereas $99 \%$ of the global volume share of vanillin was of synthetic origin (Grand View Research, 2017b). Nevertheless, the popularity and high demand for the vanilla flavour obtained from vanilla pods make vanilla one of the most expensive spices (Grand View Research, 2017a). The price of vanilla pods (containing 1-2\% vanillin) was around US\$500/kg in 2017 or even higher for a premium quality (Gelski, 2017), whereas the price for synthetic vanillin is around US\$10/kg (Bomgardner, 2016). This price gap obviously constitutes an important cause for economically motivated fraud that involves replacing natural vanillin from vanilla pods by cheaper synthetic vanillin. "Biovanillin" represents a third option to provide vanillin to the market. It is biotechnology-derived vanillin produced from natural raw materials and can be labelled as "natural vanillin" according to the European regulation 1334/2008 (European Parliament and the Council of the European Union, 2008). The labelling of food products as "natural" constitutes a powerful marketing tool. Consumers are often willing to pay a premium price for products that convey naturalness and being a healthier and safer product (Hartmann, Hieke, Taper, \& Siegrist, 2018). The most successful strategies are microorganism-based approaches using biotransformation reactions from native or genetically modified fungi, yeast, or bacteria to produce vanillin from structurally similar substrates (Fache, Boutevin, \& Caillol, 2016). Biotechnology-derived vanillin produced from rice bran/corn (ferulic acid), clove (eugenol), and turmeric (curcumin) have been marketed for more than a decade (Gallage \& Lindberg Møller, 2015). Recently, vanillin was synthesised by fermentation from glucose in the yeasts $S$. cerevisiae and Schizosaccharomyces pombe, illustrated in Figure 1 (Hansen et al., 2009; Gallage \& Lindberg Møller, 2015). However, the market price for biovanillin is still not competitive with synthetic vanillin. Much attention has been given to cost and yield optimization of biotechnologically produced vanillin in order to gain a competitive market position relative to chemically synthesised vanillin. Among the precursors used for biovanillin production, glucose is the cheapest substrate with an average cost of US\$ $0.30 / \mathrm{kg}$ (Gallage \& Lindberg Møller, 2015). Figure 2 summarises all the reported pathways for the production of vanillin that is available in the market or rather planned to be marketed in the near future. As glucose is produced from starch in principle any starch source can be used. However, the most important commercial source of starch is corn with other sources being wheat, potato, tapioca, and rice (Fellows, 2017). Sugar beet and sugar cane could theoretically also be used as glucose sources. 
Isotope ratio mass spectrometry analysis has been considered as an efficient tool for the authentication of vanillin since the $\delta^{13} \mathrm{C}$-ranges of vanillin from different precursors (petroleum, C3, C4 and CAM plants) differ from each other (Meier-Augenstein, 1999). Since the vanilla plant belongs to the CAM category, the reported delta range found for vanillin extracted from vanilla pods was from $-22.2 \%$ o to $-14.6 \%$ (Gassenmeier, Binggeli, Kirsch, \& Otiv, 2013; Greule et al., 2010). On the other hand, approximately $85 \%$ of the synthetic vanillin is produced from the petrochemical precursor guaiacol and the rest is produced from lignin obtained from C3 plants (Bomgardner, 2016). The delta ranges for synthetic vanillin were from $-36.2 \%$ o to $-24.9 \%$ (petrochemical) and $-28.7 \%$ o to $-26.5 \%$ (lignin), respectively, and thus they can easily be distinguished from natural vanillin of the vanilla pod (Hoffman \& Salb, 1979; Culp \& Noakes, 1992; Bricout, Fontes, \& Merlivat, 1974). However, the stable carbon isotope ratio of the vanillin bulk molecule ( $\left.\delta^{13} C_{\text {Bulk }}\right)$ as the analytical parameter for determining the origin has some limitations. Synthetic vanillin manipulated with synthetic vanillin enriched in ${ }^{13} \mathrm{C}$ cannot be distinguished from natural vanillin from vanilla pods by the $\delta^{13} C_{\text {Bulk }}$ value (Krueger \& Krueger, 1983). Moreover, the $\delta^{13} C_{\text {Bulk }}$ ranges for biovanillin and synthetic vanillin are overlapping when originating from C3 plants. Finally, vanillin ex ferulic acid derived from corn which is a C4 plant has been reported to overlap with vanillin ex vanilla pods (Geißler et al., 2017). It will therefore be of particular interest to investigate the $\delta^{13} \mathrm{C}$ range of vanillin ex glucose, as it can also be derived from the $\mathrm{C} 4$ plant corn.

Position-specific analysis in combination with multivariate data analysis has been applied successfully to distinguish vanillin from different sources, even when the $\delta^{13} C_{\text {Bulk }}$ values are overlapping (Geißler et al., 2017). SNIF-NMR methods (site-specific isotopic fractionation by nuclear magnetic resonance) were applied, however, large sample amounts and long analysis times are required (Guyader et al., 2019). GC-IRMS, which requires much smaller sample amounts delivers the isotopic ratio of the vanillin bulk value and, by applying the 'Zeisel reaction', also provides the stable carbon and hydrogen isotope signature of the methoxy group (Greule et al., 2010; Krueger \& Krueger, 1983).

The present research investigates biovanillin derived from glucose by GC-IRMS $\left(\delta^{13} C_{\text {Bulk, }} \delta^{2} H_{\text {Bulk, }}, \delta^{13} C_{\text {Methoxy, }}\right.$ and $\delta^{2} \mathrm{H}_{\text {Methoxy }}$ ) for the first time. Moreover, the existing database for vanillin from different sources has been extended by natural vanillin from 16 different countries, including the hybrid Vanilla $3 / 4$ Planifolia and 1/4 Pompona from Costa Rica that, to the best of the authors' knowledge, was not characterised before. The strategy to determine the authenticity of vanillin by GC-IRMS analysis of bulk vanillin combined with the position-specific analysis of the vanillin methoxy group is critically discussed against the background of the challenges that will emerge with the development of new biotechnological production methods of biovanillin in the near future. 


\section{Materials and Methods}

\subsection{Sample collection}

A total of 78 vanilla pod samples were analysed by GC-IRMS $\left(\delta^{13} \mathrm{C}_{\text {Bulk }}\right.$ and $\left.\delta^{2} \mathrm{H}_{\text {Bulk }}\right)$. The samples originate from 16 different countries: Papua New Guinea (V. planifolia) ( $n=4)$, Mexico (V. planifolia) ( $n=7)$, Congo (V. planifolia) ( $n=4), U g a n d a(V$. planifolia) ( $n=7)$, New Caledonia (V. planifolia) ( $n=4)$, Vanuatu (V. planifolia) $(n=5)$, Mauritius (V. Tahitensis) ( $n=2)$, Sri Lanka (V. planifolia) $(n=6)$, Madagascar (V. planifolia) $(n=11)$, Grand Comores (V. planifolia) $(n=4)$, Raiatea (V. Tahitensis) $(n=4)$, Cook Islands (V. Tahitensis) ( $n=4)$, Costa Rica (Hybrid V. 3/4 Planifolia and 1/4 Pompona) ( $=4$ ), Bora Bora Islands (V. planifolia) $(n=4)$, Indonesia (V. planifolia) $(n=6)$, and India (V. planifolia) $(n=2)$. Of these vanilla pods, seven samples (each from Papua New Guinea, Mexico, Vanuatu, Sri Lanka, Madagascar, and Costa Rica) were selected to isolate vanillin to analyse $\delta^{13} \mathrm{C}_{\text {Methoxy }}$ and $\delta^{2} \mathrm{H}_{\text {Methoxy }}$ by GC-IRMS. One biovanillin sample derived from glucose was provided by Professor Birger Lindberg Møller from the Plant Biochemistry Laboratory at the University of Copenhagen and analysed by GCIRMS ( $\delta^{13} C_{\text {Bulk, }} \delta^{2} H_{\text {Bulk, }} \delta^{13} C_{\text {Methoxy }}$ and $\delta^{2} H_{\text {Methoxy }}$ ). A detailed overview of the samples investigated in this study is presented in Supplementary Table 1.

\subsection{Chemicals}

The following solvents were used for extraction and isolation of vanillin: ethanol, abs. for analysis from Merck, Darmstadt (Germany), ethyl acetate, cyclohexane and dichloromethane (HPLC grade) from Rathburn Chemicals Ltd, Walkerburn (Scotland). The used water was purified with a Milli-Q water purification system from Millipore Corp. (Bedford, MA). The used chemical reagents were obtained from the following commercial sources: anhydrous sodium sulfate and disodium hydrogen phosphate dihydrate from Merck (Darmstadt, Germany), ammonium sulfate from Sigma-Aldrich Co. (St. Louis, USA), and hydriodic acid (5558\%) from Fluka (Buchs, Switzerland).

\subsubsection{Sample preparation}

\subsubsection{Vanillin extraction}

Approximately $3 \mathrm{~g}$ of the vanilla pods were split open. The seeds were scraped out and the rest of the pod was cut into pieces with a length of less than $5 \mathrm{~mm}$. The samples were placed in a closed flask with $4 \mathrm{~mL} \mathrm{H}_{2} \mathrm{O}$ and $4 \mathrm{mLEtOH}$ and macerated at ambient temperature for approximately $72 \mathrm{~h}$ during constant shaking at 60 rpm in an overhead shaker (Reax 2) from Heidolph, Germany. Afterwards, the mixture was filtered with a filter paper (Whatman ${ }^{\mathrm{TM}}$ ). A total of $3 \mathrm{~mL}$ of the ethanol/water extract was further extracted with $3 \mathrm{~mL}$ of ethyl acetate/cyclohexane (1:1) and dried with anhydrous sodium sulfate. The extracts were not diluted before analyses by GC-HTC-IRMS. For GC-C-IRMS analyses, the samples were 1:4 diluted with ethyl acetate/cyclohexane (1:1). 


\subsubsection{Vanillin isolation}

The filtrate from the vanillin extraction procedure was used for the isolation of vanillin from the vanilla pods. $0.4 \mathrm{~g}$ of $\mathrm{Na}_{2} \mathrm{HPO}_{4}$ and $1.3 \mathrm{~g}$ of $\left(\mathrm{NH}_{4}\right)_{2} \mathrm{SO}_{4}$ per $2 \mathrm{~g}$ vanilla pod were added. The mixture was stirred until a clear separation between the aqueous and organic phases was achieved. The organic phase was collected and applied on preparative thin-layer chromatography plates (silica gel matrix with fluorescent indicator, Merck (Germany). Dichloromethane was used as the mobile phase for the chromatographic separation. The vanilla compounds were detected by UV light and was collected by scraping the silica from the plates. The vanillin was extracted from the silica with ethyl acetate in an ultrasound bath for $5 \mathrm{~min}$. The mixture was filtered to remove the silica. The purity of the vanillin was checked by GC-MS. Lastly, ethyl acetate was evaporated. The same sample procedure was also performed with a vanillin standard to exclude isotopic fractionation during the isolation process.

\subsubsection{Sample preparation - analysis of vanillin methoxy groups}

Analyses of vanillin methoxy groups were conducted as previously described (Greule et al., 2010). 1-2 mg of pure vanillin was used for the carbon analyses, and 4-7 mg was used for the hydrogen analyses.

\subsubsection{GC-IRMS Instrumentation}

All stable isotope measurements were performed as previously described (Geißler et al., 2017). These measurements were performed using a gas chromatography-combustion/high temperature conversionisotope ratio mass spectrometry (GC-C/HTC-IRMS) system consisting of an HP $6890 \mathrm{~N}$ gas chromatograph (Agilent, Santa Clara, CA, USA) equipped with an A200S autosampler (CTC Analytics, Zwingen, Switzerland), coupled to a DeltaPLUS XL isotope ratio mass spectrometer (ThermoQuest Finnigan, Bremen, Germany) via an oxidation reactor $\left({ }^{13} \mathrm{C}\right)$ [ceramic tube $\left(\mathrm{Al}_{2} \mathrm{O}_{3}\right)$, length $320 \mathrm{~mm}, 0.5 \mathrm{~mm}$ i.d., with $\mathrm{Cu} / \mathrm{Ni} / \mathrm{Pt}$ wires inside (activated by oxygen), reactor temperature $960{ }^{\circ} \mathrm{C}$ ] or via a pyrolysis reactor $\left(\delta^{2} \mathrm{H}\right)$ [ceramic tube $\left(\mathrm{Al}_{2} \mathrm{O}_{3}\right)$, length $320 \mathrm{~mm}, 0.5 \mathrm{~mm}$ i.d., reactor temperature $1450^{\circ} \mathrm{C}$ ] and a GC Combustion III interface (ThermoQuest Finnigan, Bremen, Germany). A tank of high purity carbon dioxide 4.8 (Kohlendioxid ISO-TOP, Air Liquide, Düsseldorf, Germany) was used as the working reference gas for carbon stable isotope analysis. For hydrogen stable isotope analysis, a tank of high purity hydrogen gas 6.0 (Alphagaz ${ }^{\mathrm{TM}} 2 \mathrm{H}_{2}$, Air Liquide, Düsseldorf, Germany) was used as the working reference gas.

Throughout this paper, the conventional 'delta' notation is used. $\delta^{2} \mathrm{H}$ values relative to $\mathrm{V}-\mathrm{SMOW}$ and $\delta^{13} \mathrm{C}$ values relative to $\mathrm{V}-\mathrm{PDB}$ are defined as:

$$
\delta^{\mathrm{i}} \mathrm{E}=\left(\left({ }^{\mathrm{i}} \mathrm{R}_{\text {sample }}-{ }^{\mathrm{i}} \mathrm{R}_{\text {reference }}\right) /{ }^{\mathrm{i}} \mathrm{R}_{\text {reference }}\right)
$$


156

157

158

159

160

161

162

163

164

165

166

167

168

169

170

171

172

173

174

175

176

177

178

179

180

181

where ${ }^{i}$ is the mass number of the heavier isotope of the element $E, R_{\text {sample }}$ is the respective isotope ratio of the sample and $R_{\text {reference }}$ is the isotope ratio of the relevant internationally recognised reference material. The delta values are multiplied by 1000 and expressed in "per mil" (\%о) (Coplen, 2011; Brand, Coplen, Vogl, Rosner, \& Prohaska, 2014).

\subsubsection{Bulk analysis}

For both, $\delta^{13} \mathrm{C}$ and $\delta^{2} \mathrm{H}$ bulk analysis, $1 \mu \mathrm{l}$ of dissolved vanillin samples was automatically injected into the GCC/HTC-IRMS system. Corrections of the vanillin bulk values were made against a vanillin working standard $\left(\delta^{13} \mathrm{C}=-29.06 \%\right.$ o, $\delta^{2} \mathrm{H}=79.7 \%$ ) (Greule et al., 2010).

\subsubsection{Analysis of methoxy groups}

Hydrogen and carbon isotopic signatures of vanillin methoxy groups were measured as $\mathrm{CH}_{3}$ l released upon treatment of vanillin samples with $\mathrm{HI}$ as previously described (Greule et al., 2009, 2010). The gas chromatograph was fitted with a ZB-5 ms capillary column (Phenomenex, Torrance, CA, USA) (30 m*0.25 mm i.d., $\left.d_{f} 1.0 \mathrm{~mm}\right)$.

The GC conditions for $\delta^{13} \mathrm{C}$ analysis were: split injection (split ratio $10: 1$ ), injector temperature $200^{\circ} \mathrm{C}$; initial oven temperature at $30^{\circ} \mathrm{C}$ for $3.8 \mathrm{~min}$, ramp at $30^{\circ} \mathrm{C} / \mathrm{min}$ to $100^{\circ} \mathrm{C}$. Helium was used as the carrier gas and the flow rate was $1.8 \mathrm{~mL} / \mathrm{min}$. Regarding $\delta^{2} \mathrm{H}$ analysis, the following $\mathrm{GC}$ conditions were employed: split injection (split ratio 4:1), injector temperature $200^{\circ} \mathrm{C}$; initial oven temperature at $30^{\circ} \mathrm{C}$ for $7 \mathrm{~min}$, ramp at 40 ${ }^{\circ} \mathrm{C} / \mathrm{min}$ to $120^{\circ} \mathrm{C}$ with a constant helium carrier gas flow of $0.6 \mathrm{~mL} / \mathrm{min}$.

All $\delta^{13} \mathrm{C}$ and $\delta^{2} \mathrm{H}$ values were normalized relative to V-PDB or V-SMOW by a two-point calibration using two $\mathrm{CH}_{3}$ l standards with distinct isotope signatures. $\delta^{13} \mathrm{C}$ and $\delta^{2} \mathrm{H}$ values of $\mathrm{CH}_{3}$ l were calibrated against international reference substances (NBS-19 (+1.95\%) and NBS-22 (-30.03 $\pm 0.04 \%$ ) for carbon; VSMOW2 (0 $\pm 0.3 \%$ ) and SLAP2 $(-427.5 \pm 0.3 \%$ ) for hydrogen using TC/EA-IRMS (elemental analyser-isotopic ratio mass spectrometer, IsoLab, Max Planck Institute for Biogeochemistry, Jena, Germany). The calibrated $\delta^{13} \mathrm{C}$ values vs. V-PDB for the two $\mathrm{CH}_{3}$ l working standards were $-70.04 \pm 0.13 \%$ o $(n=5,1 \sigma)$ and $-60.72 \pm 0.05 \%$ ( $n=7,1$ $\sigma)$. The calibrated $\delta^{2} H$ values vs. V-SMOW were $-173.0 \pm 1.5 \%$ o $(n=9,1 \sigma)$ and $-66.2 \pm 1.2 \%$ o $(n=8,1 \sigma) . \mathrm{CH}_{3} \mathrm{l}$ standard measurements were performed after every fifth sample injection. 


\section{Results and discussion}

183

184

185

186

187

188

189

190

191

192

193

194

195

196

197

198

199

200

201

202

203

204

205

206

207

208

209

210

211

\section{Analysis of $\delta^{13} C_{B u l k}$ value of vanillin derived from glucose}

For vanillin ex glucose, a $\delta^{13} \mathrm{C}_{\text {Bulk }}$ value of $-12.5 \%$ was determined. The botanical origin of the glucose is not known in this case. However, a $\delta^{13} C_{\text {Bulk }}$ value of $-11 \%$ o was reported for glucose obtained from C4 plants, while a value of about -25\% was reported for glucose derived from C3 plants (Meier-Augenstein, 1999). It is therefore likely that the here analysed vanillin originates from glucose that was obtained from a C4 plant, for example, corn. It is the first time a $\delta^{13} \mathrm{C}$ value for biovanillin is reported that is higher compared to vanillin from vanilla pods.

More vanillin samples ex glucose obtained from known sources (e.g., rice, potato, or corn) should be investigated to fill the current data gap about vanillin from these sources. So far, highly priced ${ }^{13} \mathrm{C}$ enriched vanillin is required for adulteration of synthetic vanillin in order to match the $\delta^{13} C_{\text {Bulk }}$ range for vanillin from vanilla pods. A cheap source of vanillin enriched in ${ }^{13} \mathrm{C}$ will make it easier to simulate the $\delta^{13} \mathrm{C}_{\text {Bulk }}$ value of vanillin from vanilla pods by mixing vanillin from the respective sources, which can increase the risk of fraud being perpetrated while remaining unnoticed by the analysis of $\delta^{13} C_{\text {Bulk }}$ values. However, several studies on purified vanillin have demonstrated that additional information about the $\delta^{2} \mathrm{H}$ values as well as positionspecific isotope analysis of stable hydrogen and carbon enables the distinction of vanillin obtained from different precursors even if the $\delta^{13} C_{\text {Bulk }}$ ranges overlap (Geißler et al., 2017; Tenailleau, Lancelin, Robins, \& Akoka, 2004; Guyader et al., 2019).

\section{$\underline{\delta^{13} \mathrm{C} \text { and } \delta^{2} \mathrm{H} \text { analyses of bulk vanillin and vanillin methoxy groups }}$}

Previous studies have reported the $\delta^{13} \mathrm{C}$ and $\delta^{2} \mathrm{H}$ values of bulk vanillin and vanillin methoxy groups from different vanillin samples, showing a clustering of the samples from the same source (Geißler et al., 2017; Greule et al., 2010). These literature data have been combined with the acquired data here in order to compare vanillin ex glucose with known vanillin products from different sources. Figure 3 shows the 2D plot of the $\delta^{13} \mathrm{C}_{\text {Bulk }}$ vs. $\delta^{2} \mathrm{H}_{\text {Bulk }}$ values of the combined data, illustrating that vanillin ex glucose (red spot) is clearly distinguished from vanillin derived from all other sources. Figure 3 further displays that the values of the vanillin ex vanilla pods lies between the values of vanillin ex eugenol (or guaiacol) and those of vanillin ex glucose. It can thus be inferred that a combination of these sources can lead to an imitation of the $\delta^{13} \mathrm{C}$ and the $\delta^{2} \mathrm{H}$ bulk values of vanillin ex vanilla pods.

The data acquired in this study (Figure 3) represent the results of the $\delta^{13} \mathrm{C}$ and $\delta^{2} \mathrm{H}$ bulk values of vanillin ex vanilla pods from 16 different countries. This additional data assert that it is not possible to reliably separate 
authentic vanillin ex vanilla pods from vanillin ex ferulic acid (corn) by solely analysing the $\delta^{13} C_{\text {Bulk }}$ and $\delta^{2} H_{\text {Bulk. }}$ The measured values of vanillin from vanilla pods in our work lie even closer to the values of vanillin ex ferulic acid (corn), in agreement with the previous findings in the literature (Geißler et al., 2017). Considering the hybrid Vanilla $3 / 4$ Planifolia and $1 / 4$ Pompona, the $\delta^{13} \mathrm{C}$ and $\delta^{2} \mathrm{H}$ bulk values of the three vanillin samples from this hybrid (green circles) are found to overlap with those of the samples from the species Vanilla Planifolia (Figure 3).

Furthermore, the $\delta^{13} \mathrm{C}$ and $\delta^{2} \mathrm{H}$ data of the methoxy groups of vanillin ex glucose and vanillin extracted from seven vanilla pods have been compared with the data from existing studies (Figure 4). It can again be observed in the plot of $\delta^{13} \mathrm{C}_{\text {Methoxy }}$ and $\delta^{2} \mathrm{H}_{\text {Methoxy }}$ that the samples of vanillin derived from vanilla pods lie between vanillin samples ex eugenol (or guaiacol) and vanillin ex glucose. This means that by an appropriate mixture, not only the $\delta^{13} \mathrm{C}$ and $\delta^{2} \mathrm{H}$ bulk values might be imitated, but also the stable isotope values of vanillin methoxy groups.

The vanillin samples from different precursor groups were distinguished either in the $\delta^{13} C_{\text {Bulk }}$ vs. $\delta^{2} \mathrm{H}_{\text {Bulk }}$ plot or rather in the $\delta^{13} \mathrm{C}_{\text {Methoxy }}$ vs. $\delta^{2} \mathrm{H}_{\text {Methoxy }}$ plot (Geißler et al., 2017). However, it must be taken into consideration that before using the four parameters $\left(\delta^{13} C_{\text {Bulk }}, \delta^{13} C_{\text {Methoxy, }} \delta^{2} H_{\text {Bulk }}\right.$ and $\left.\delta^{2} H_{\text {Methoxy }}\right)$ for reliable prediction of an unknown sample, a representative sample set covering the natural variability of each group is required. The $\delta^{2} \mathrm{H}$-value of a sample is linked to the climatic conditions and geographical characteristics of the place where the sample has grown (Smith \& Ziegler, 1990; International Atomic Energy Agency, 2019). Therefore, $\delta^{2} \mathrm{H}$-values with a high variability must be expected for plants such as corn that can be cultivated in widespread areas, (CGIAR Research Program on Maize, 2016).

A further approach to assess the origin of vanillin samples is to plot the $\delta^{2} \mathrm{H}$ values of bulk vanillin against the $\delta^{2} \mathrm{H}$ values of the vanillin methoxy groups (Figure 5). This correlation might benefit from the fact that the $\delta^{2} H_{\text {Methoxy }}$ values of the plant material are highly depleted compared to the $\delta^{2} H$ values of the source water as a result of a large uniform biosynthetic fractionation (Keppler \& Hamilton, 2008; Anhäuser, Greule, Polag, Bowen, \& Keppler, 2017). However, the $\delta^{2} \mathrm{H}_{\text {Bulk }}$ value more or less reflects the stable hydrogen isotopic signature of the source water (Sternberg, 1988; (Keppler et al., 2007). Thus, the correlation between $\delta^{2} \mathrm{H}_{\text {Methoxy }}$ and $\delta^{2} \mathrm{H}_{\text {Bulk }}$ represents this biosynthetic fractionation in good approximation. As this fractionation has been shown to be plant species-specific (Greule, Rossmann, Schmidt, Mosandl, \& Keppler, 2015), varying natural sources serving as vanillin precursors like corn, rice, or potatoes might have different

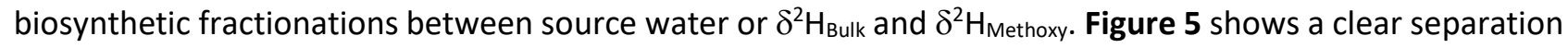
of the samples of vanillin ex ferulic acid (corn) from the samples of vanillin ex vanilla pods which might be 
influenced by different biosynthetic fractionations as stated before. On the other hand, while all samples of vanillin ex pods show an average fractionation between $\delta^{2} \mathrm{H}_{\text {Bulk }}$ and $\delta^{2} \mathrm{H}_{\text {Methoxy }}$ of $-124 \%$, both samples of vanillin ex ferulic acid (corn) fractionate by only -26 and -22\%o, respectively (Figure 5). This discrepancy is not explainable up to now but can be probably attributed to processes during the extraction of ferulic acid from corn and/or biosynthesis of vanillin by fermentative bioconversion. It is highly unlikely that $\delta^{2} \mathrm{H}_{\text {Methoxy }}$ of corn will not exhibit a large biosynthetic fractionation to source water or $\delta^{2} \mathrm{H}_{\text {Bulk, }}$, although this has not been analysed yet. However, the differentiation of vanillin ex vanilla pods from vanillin ex ferulic acid (corn) based on the ratio of $\delta^{2} \mathrm{H}_{\text {Bulk }}$ to $\delta^{2} \mathrm{H}_{\text {Methoxy }}$ must be confirmed by extending the respective sample sets. Moreover, the correlation $\delta^{2} \mathrm{H}_{\text {Methoxy }} / \delta^{2} \mathrm{H}_{\text {Bulk }}$ might have the potential to separate vanillin ex glucose from authentic vanillin samples due to the most negative $\delta^{2} \mathrm{H}$ values in both, bulk and methoxy group Figure 5. Nevertheless, it must be emphasized again that it is mandatory to analyse more vanillin ex glucose samples for a reliable assessment.

Another analytical technique for the authentication of vanillin is the determination of ${ }^{13} \mathrm{C}$ and ${ }^{2} \mathrm{H}-\mathrm{SNIF}-\mathrm{NMR}$ isotopic fingerprints. Recently, vanillin ex ferulic acid (corn) has also been included in a database where vanillin from different precursors (ferulic acid (rice), eugenol, cucurmin, lignin, guaiacol, vanilla pods) were investigated (Guyader et al., 2019). The ${ }^{13} \mathrm{C}$ isotopic profiles allowed a promising distinction of all of the precursor groups. However, a proximity between vanillin ex ferulic acid from corn and vanillin ex vanilla pods was observed, whereas these two groups were better separated by the ${ }^{2} \mathrm{H}$ isotopic profiles. This is in accordance with the GC-IRMS results where the $\delta^{13} C_{\text {Bulk }}$ and $\delta^{13} C_{\text {Methoxy }}$ of vanillin ex ferulic acid (corn) and ex vanilla pods are overlapping, while a separation can be observed when comparing the values for $\delta^{2} \mathrm{H}_{\text {Bulk }}$ and $\delta^{2} \mathrm{H}_{\text {Methoxy }}$ of both groups. One of the aims of the SNIF-NMR analysis is to reduce the needed sample amount which might open the possibility to analyse vanillin isolated from food products by SNIF-NMR (Guyader et al., 2019). In contrast to that, only a small amount of vanillin is needed for the analysis by GC-IRMS in combination with the Zeisel method. This method is therefore more appropriate to analyse quite small Anyway, biovanillin ex glucose is expected to enter the market. The results of this study for vanillin ex glucose are alarming, as cheap vanillin enriched in ${ }^{13} \mathrm{C}$ opens an easy route to fraudulently simulate the $\delta^{13} C_{\text {Bulk }}$ range of vanillin from vanilla pods. This is particularly relevant as the $\delta^{13} C_{\text {Bulk }}$ value is often the parameter used to determine the authenticity of vanillin incorporated in food products (Schipilliti, Bonaccorsi, \& Mondello, 2016; Lamprecht \& Blochberger, 2009; Bononi, Quaglia, \& Tateo, 2015). 


\section{Conclusion}

275 Comparing stable hydrogen and carbon isotope composition of vanillin ex glucose with the current database 276 highlights that i) there is an urgent need for an isotopic characterisation of vanillin ex glucose based on a 277 sufficient sample set, ii) the mix of synthetic/biosynthetic vanillin with vanillin ex glucose can provide a cost278 efficient opportunity to fraudulently simulate the $\delta^{13} C_{\text {Bulk }}$ range for vanillin from vanilla pods, and iii) there is 279 an increased risk that biosynthetic vanillin will be sold as vanillin from vanilla pods when used as an ingredient 280 in processed foods like ice cream. It was shown that the analysed vanillin ex glucose sample can be 281 distinguished from vanillin of other sources by GC-IRMS. Moreover, data from vanillin ex glucose (obtained 282 from different precursors like corn, potato, and rice) should be integrated into existing SNIF-NMR-databases, 283 since this technique also delivers promising results for the distinction of vanillin of different precursors. The 284 intention of this study is to encourage the extension of the database for biovanillin from different precursors, 285 especially as vanillin ex glucose and vanillin ex ferulic acid from corn have the potential to complicate the 286 authentication of natural vanilla flavour from vanilla beans in the future.

\section{Acknowledgement}

288 The authors would like to thank Professor Birger Lindberg Møller, Plant Biochemistry Laboratory at the University of Copenhagen for supplying vanillin derived from glucose for this project.

\section{Conflict of interest statement}

291 The authors declare no conflict of interest. 


\section{References}

Anhäuser, T., Greule, M., Polag, D., Bowen, G. J., \& Keppler, F. (2017). Mean annual temperatures of midlatitude regions derived from $\delta 2 \mathrm{H}$ values of wood lignin methoxyl groups and its implications for paleoclimate studies. Science of the Total Environment, 574, 1276-1282. https://doi.org/10.1016/j.scitotenv.2016.07.189

Bomgardner, M. M. (2016). The problem with vanilla. Chemical and Engineering News, 94(36), 38-42. https://doi.org/10.1021/cen-09436-cover

Bononi, M., Quaglia, G., \& Tateo, F. (2015). Easy Extraction Method to Evaluate d13C Vanillin by Liquid Chromatography-Isotopic Ratio Mass Spectrometry in Chocolate Bars and Chocolate Snack Foods. Journal of Agricultural and Food Chemistry, 63(19), 4777-4781. https://doi.org/10.1021/acs.jafc.5b02136

Brand, W. A., Coplen, T. B., Vogl, J., Rosner, M., \& Prohaska, T. (2014). Assessment of international reference materials for isotope-ratio analysis (IUPAC Technical Report). Pure and Applied Chemistry, 86(3), 425-467. https://doi.org/10.1515/pac-2013-1023

Bricout, J., Fontes, J.-C., \& Merlivat, L. (1974). Detection of Synthetic Vanillin in Vanilla Extracts by Isotopic Analysis. J. Assoc. Off. Anal. Chem., 1(57), 713-715.

CGIAR Research Program on Maize. (2016). Challenges and opportunities - Maize production. Retrieved February 11, 2019, from https://maize.org/challenges-and-opportunities/

Coplen, T. B. (2011). Guidelines and recommended terms for expression of stable-isotope-ratio and gasratio measurement results. Rapid Communications in Mass Spectrometry, 25(17), 2538-2560. https://doi.org/10.1002/rcm.5129

Culp, R. A., \& Noakes, J. E. (1992). Determination of Synthetic Components in Flavors by Deuterium/Hydrogen Isotopic Ratios. Journal of Agricultural and Food Chemistry, 40(10), 1892-1897. https://doi.org/10.1021/jf00022a033

Dignum, M. J. W., Kerler, J., \& Verpoorte, R. (2001). Vanilla Production: Technological, Chemical, and Biosynthetic Aspects. Food Reviews International, 17(2), 119-120. https://doi.org/10.1081/FRI100000269

European Parliament and the Council of the European Union. (2008). Regulation (EC) No 1334/2008. Official Journal of the European Union, L 354/34(1334), 34-50. Retrieved from http://eurlex.europa.eu/legal-content/EN/TXT/?uri=celex:32008R1334

Fache, M., Boutevin, B., \& Caillol, S. (2016). Vanillin Production from Lignin and Its Use as a Renewable Chemical. ACS Sustainable Chemistry and Engineering, 4(1), 35-46. https://doi.org/10.1021/acssuschemeng.5b01344

Fellows, P. J. (2017). Properties of food and principles of processing. In Food processing technology : principles and practice (4th ed., pp. 3-200). Woodhead Publishing. https://doi.org/10.1016/B978-008-100522-4.00001-8

Gallage, N. J., \& Lindberg Møller, B. (2015). Vanillin-bioconversion and bioengineering of the most popular plant flavor and its de novo biosynthesis in the vanilla orchid. Molecular Plant, 8(1), 40-57. https://doi.org/10.1016/j.molp.2014.11.008 
Gassenmeier, K., Binggeli, E., Kirsch, T., \& Otiv, S. (2013). Modulation of the $13 \mathrm{C} / 12 \mathrm{C}$ ratio of vanillin from vanilla beans during curing. Flavour and Fragrance Journal, 28(1), 25-29. https://doi.org/10.1002/ffj.3122

Geißler, K., Greule, M., Schäfer, U., Hans, J., Geißler, T., Meier, L., ... Krammer, G. (2017). Vanilla authenticity control by DNA barcoding and isotope data aggregation. Flavour and Fragrance Journal, 32(4), 228-237. https://doi.org/10.1002/ffj.3379

Gelski, J. (2017). Vanilla prices shoot up, near $\$ 500$ per kilogram. Retrieved January 18,2019 , from https://www.foodbusinessnews.net/articles/8953-vanilla-prices-shoot-up-near-500-per-kilogram

Grand View Research. (2017a). Vanillin Market Analysis. Retrieved November 1, 2018, from https://www.grandviewresearch.com/industry-analysis/vanillin-market

Grand View Research. (2017b). Vanillin Market Size Worth \$724.5 Million By 2025- Growth Rate: 7.0\%. Retrieved January 24, 2018, from https://www.grandviewresearch.com/press-release/global-vanillinmarket

Greule, M., Mosandl, A., Hamilton, J. T. g., \& Keppler, F. (2009). A simple rapid method to precisely determine $13 \mathrm{C} / 12 \mathrm{C}$ ratios of plant methoxyl groups. Rapid Communications in Mass Spectrometry: RCM, 23(11), 1710-1714. https://doi.org/10.1002/rcm.4057

Greule, M., Rossmann, A., Schmidt, H. L., Mosandl, A., \& Keppler, F. (2015). A stable isotope approach to assessing water loss in fruits and vegetables during storage. Journal of Agricultural and Food Chemistry, 63(7), 1974-1981. https://doi.org/10.1021/jf505192p

Greule, M., Tumino, L. D., Kronewald, T., Hener, U., Schleucher, J., Mosandl, A., \& Keppler, F. (2010). Improved rapid authentication of vanillin using $\delta 13 \mathrm{C}$ and $\delta 2 \mathrm{H}$ values. European Food Research and Technology, 231(6), 933-941. https://doi.org/10.1007/s00217-010-1346-z

Guyader, S., Thomas, F., Jamin, E., Grand, M., Akoka, S., Silvestre, V., \& Remaud, G. S. (2019). Combination of $13 \mathrm{C}$ and $2 \mathrm{H}$ SNIF-NMR isotopic fingerprints of vanillin to control its precursors. Flavour and Fragrance Journal, 34(2), 133-144. https://doi.org/10.1002/ffj.3486

Hansen, A. M. S., Fromberg, A., \& Frandsen, H. L. (2014). Authenticity and traceability of vanilla flavors by analysis of stable isotopes of carbon and hydrogen. Journal of Agricultural and Food Chemistry, 62(42), 10326-10331. https://doi.org/10.1021/jf503055k

Hansen, E. H., Møller, B. L., Kock, G. R., Bünner, C. M., Kristensen, C., Jensen, O. R., ... Hansen, J. (2009). De novo biosynthesis of Vanillin in fission yeast (schizosaccharomyces pombe) and baker's yeast (saccharomyces cerevisiae). Applied and Environmental Microbiology, 75(9), 2765-2774. https://doi.org/10.1128/AEM.02681-08

Hartmann, C., Hieke, S., Taper, C., \& Siegrist, M. (2018). European consumer healthiness evaluation of 'Free-from' labelled food products. Food Quality and Preference, 68, 377-388. https://doi.org/10.1016/j.foodqual.2017.12.009

Hoffman, P., \& Salb, M. (1979). Isolation and stable isotope ratio analysis of vanillin. Journal of Agricultural and Food Chemistry, 27(2), 352-355. Retrieved from http://pubs.acs.org/doi/abs/10.1021/jf60222a036

International Atomic Energy Agency. (2019). RCWIP (Regionalized Cluster-Based Water Isotope Prediction) Model - gridded precipitation $\delta 180|\delta 2 \mathrm{H}| \delta 180$ and $\delta 2 \mathrm{H}$ isoscape data. Retrieved March 7, 2019, 
Keppler, F., \& Hamilton, J. (2008). Tracing the geographical origin of early potato tubers using stable hydrogen isotope ratios of methoxyl groups. Isotopes in Environmental and Health Studies, 44(4), 337-347. https://doi.org/10.1080/10256010802507383

Keppler, F., Harper, D. B., Kalin, R. M., Meier-Augenstein, W., Farmer, N., Davis, S., ... Hamilton, J. T. G. (2007). Stable hydrogen isotope ratios of lignin methoxyl groups as a paleoclimate proxy and constraint of the geographical origin of wood. New Phytologist, 176(3), 600-609. https://doi.org/10.1111/j.1469-8137.2007.02213.x

Korthou, H., \& Verpoorte, R. (2007). Vanilla. In R. G. Berger (Ed.), Flavours and Fragrances: Chemistry, Bioprocessing and Sustainability (pp. 203-217). Berlin Heidelberg: Springer. https://doi.org/10.1007/978-3-540-49339-6

Krueger, D. A., \& Krueger, H. W. (1983). Carbon isotopes in vanillin and the detection of falsified natural vanillin. Section Title: Food and Feed Chemistry, 31(6), 1265-1268. https://doi.org/10.1021/jf00120a030

Lamprecht, G., \& Blochberger, K. (2009). Protocol for isolation of vanillin from ice cream and yoghurt to confirm the vanilla beans origin by 13C-EA-IRMS. Food Chemistry, 114(3), 1130-1134. https://doi.org/10.1016/j.foodchem.2008.10.071

Meier-Augenstein, W. (1999). Applied gas chromatography coupled to isotope ratio mass spectrometry. Journal of Chromatography A, 842(1-2), 351-371. https://doi.org/10.1016/S0021-9673(98)01057-7

Schipilliti, L., Bonaccorsi, I. L., \& Mondello, L. (2016). Characterization of natural vanilla flavour in foodstuff by HS-SPME and GC-C-IRMS. Flavour and Fragrance Journal, 32(2), 85-91. https://doi.org/10.1002/ffj.3364

Smith, B. N., \& Ziegler, H. (1990). Isotopic Fractionation of Hydrogen in Plants. Botanica Acta, 103(4), 335342. https://doi.org/10.1111/j.1438-8677.1990.tb00171.x

Sternberg, L. da S. L. S. (1988). D/H ratios of environmental water recorded by D/H ratios of plant lipids. Nature, 333(6168), 59-61.

Tenailleau, E., Lancelin, P., Robins, R. J., \& Akoka, S. (2004). NMR approach to the quantification of nonstatistical 13C distribution in natural products: Vanillin. Analytical Chemistry, 76(13), 3818-3825. https://doi.org/10.1021/ac0496998 